\title{
Expectations, mood, and eating behavior in binge eating disorder. Beware of the bright side
}

Citation for published version (APA):

Dingemans, A., Martijn, C., van Furth, E., \& Jansen, A. T. M. (2009). Expectations, mood, and eating behavior in binge eating disorder. Beware of the bright side. Appetite, 53, 166-173.

https://doi.org/10.1016/j.appet.2009.06.002

Document status and date:

Published: 01/01/2009

DOI:

10.1016/j.appet.2009.06.002

Document Version:

Publisher's PDF, also known as Version of record

Document license:

Taverne

Please check the document version of this publication:

- A submitted manuscript is the version of the article upon submission and before peer-review. There can be important differences between the submitted version and the official published version of record.

People interested in the research are advised to contact the author for the final version of the publication, or visit the DOI to the publisher's website.

- The final author version and the galley proof are versions of the publication after peer review.

- The final published version features the final layout of the paper including the volume, issue and page numbers.

Link to publication

\footnotetext{
General rights rights.

- You may freely distribute the URL identifying the publication in the public portal. please follow below link for the End User Agreement:

www.umlib.nl/taverne-license

Take down policy

If you believe that this document breaches copyright please contact us at:

repository@maastrichtuniversity.nl

providing details and we will investigate your claim.
}

Copyright and moral rights for the publications made accessible in the public portal are retained by the authors and/or other copyright owners and it is a condition of accessing publications that users recognise and abide by the legal requirements associated with these

- Users may download and print one copy of any publication from the public portal for the purpose of private study or research.

- You may not further distribute the material or use it for any profit-making activity or commercial gain

If the publication is distributed under the terms of Article $25 \mathrm{fa}$ of the Dutch Copyright Act, indicated by the "Taverne" license above, 
Research report

\title{
Expectations, mood, and eating behavior in binge eating disorder. Beware of the bright side
}

\author{
Alexandra E. Dingemans ${ }^{\text {a, }}$, Carolien Martijn ${ }^{\text {b }}$, Eric F. van Furth ${ }^{\mathrm{a}}$, Anita T.M. Jansen ${ }^{\mathrm{b}}$ \\ a Center for Eating Disorders 'Ursula', PO Box 422, 2260 AK Leidschendam, The Netherlands \\ ${ }^{\mathrm{b}}$ Department of Clinical Psychological Sciences, PO Box 616, 6200 MD Maastricht University, Maastricht, The Netherlands
}

A R T I C L E I N F O

\section{Article history:}

Received 3 February 2009

Received in revised form 13 May 2009

Accepted 1 June 2009

\section{Keywords:}

Binge eating disorder

Expectations

Depression

Experiment

Overeating

Negative affect

Positive affect

Mood induction

Food exposure

Emotion regulation

\begin{abstract}
A B S T R A C T
Sad people may indulge in fattening snacks because they believe that eating will repair their mood. To test whether (1) changes in expectations and mood had an effect on caloric intake and (2) depressive symptoms moderated caloric intake, 73 women with binge eating disorder were randomly assigned to a condition in which expectations about food and emotion were either confirmed or disconfirmed. Subsequently they were shown either an upsetting or an amusing movie clip followed by a taste task. Contrary to our expectations, there were no differences in the four conditions: participants in all four conditions ate comparable amounts of calories. Manipulation of expectations or mood had no effect on caloric intake. However, higher baseline expectations that food is pleasurable and useful as a reward resulted in a higher caloric intake after positive mood induction. Non-depressed individuals ate less after a negative mood induction than did depressed individuals. Interestingly, they also ate less than the group of individuals, depressed and not, whose mood was positively induced. Non-depressed individuals seem to use healthier coping strategies: negative affect signals that the environment poses a problem. Positive affect on the other hand signals that the environment is benign, and thus makes people less vigilant about food intake.
\end{abstract}

(c) 2009 Elsevier Ltd. All rights reserved.

\section{Introduction}

Negative mood states influence eating behaviors in patients with binge eating disorder (BED). Several cross-sectional and therapy outcome studies suggest that depressive symptoms (trait), acute negative mood (state), and binge eating behavior are related (Antony, Johnson, Carr-Nangle, \& Abel, 1994; Dingemans, Spinhoven, \& Van Furth, 2007; Grilo \& Shiffman, 1994; Grilo, Masheb, \& Wilson, 2001; Mussell et al., 1996; Peterson, Thuras, Crow, Mitchell, \& Miller, 2005; Stice et al., 2001; Telch \& Agras, 1994). There are indications that more severe binge eating is related to higher levels of depression (Antony et al., 1994; Grilo et al., 2001; Stice et al., 2001). Binge eating might serve as an attempt to manage of alleviate negative affect (Heatherton \& Baumeister, 1991). The findings about the causality of mood and binge eating however are inconclusive. Four experimental studies (Agras \& Telch, 1998; Chua, Touyz, \& Hill, 2004; Munsch, Meyer, Margraf, Michael, \& Biedert, 2008; Telch \& Agras, 1996a) investigated the causal relation between mood and binge eating in patients with

\footnotetext{
* Corresponding author.

E-mail address: a.dingemans@centrumeetstoornissen.nl (A.E. Dingemans).
}

BED. One study (Chua et al., 2004) found that acute negative mood elicited increased eating in patients with BED compared to a neutral mood. Three other studies did not find differences in calories consumed following negative or neutral mood induction (Telch et al., 1996a; Agras et al., 1998; Munsch et al., 2008). One hypothesis was that negative mood might influence BED participants' perception of their eating behavior, and therefore lead to the labeling of an eating episode as a binge (Telch \& Agras, 1996b; Agras et al., 1998). Another suggestion was that binge eating often occurs in negative moods because eating decreases negative mood rather than negative mood being a trigger for binge eating (Munsch et al., 2008).

The pervasiveness of the association between emotional distress and binge eating suggests that the question is not whether but how negative affect leads to overeating. Sad people often indulge in fattening snacks because they believe that eating repairs their mood (Deaver, Meidinger, Crosby, Miltenberger, \& Smyth, 2003; Macht \& Mueller, 2007; Tice, Bratslavsky, \& Baumeister, 2001). Behavior, and especially persistent efforts to control oneself, are strongly influenced by people's expectations and cognitions about how self-control works (Martijn, Tenbult, Merckelbach, Dreezens, \& de Vries, 2002). People tend to abandon or violate their normal self-regulatory efforts because they give priority to affect 
regulation. It might be hypothesized that they expect that fattening foods will improve their mood.

Several authors have stated that eating, apart from physiological, environmental and social cues, may be affected by and associated with emotions (Desmet \& Schifferstein, 2008; Dunn, Mohr, Wilson, \& Wittert, 2008; Greeno \& Wing, 1994; Macht \& Dettmer, 2006; Macht \& Simons, 2000). For example in everyday life frequent associations between food and emotions are made. An example is the recently launched media campaign by Mars ${ }^{\circledR}$ in which the name "Mars ${ }^{\mathbb{R}}$ " is temporarily replaced by "happy", "love," or "feel good" on the wrapper of the well-known chocolate bar. Frequent exposure to these kinds of messages in the media and elsewhere influences people's expectations regarding food and mood. The expectancy learning theory postulates that one forms expectations of the consequences of various behaviors as a result of one's learning history (Smith, Simmons, Flory, Annus, \& Hill, 2007). These expectations influence future behavioral choices. Expectations about the consequences of a given behavior are the sum of one's learning history and are thus the cognitive mechanism by which prior learning leads to subsequent behavior. The temporal association of negative affect with binge eating implies that perhaps bingers have learned to anticipate reduction of distress from binging (Hohlstein, Smith, \& Atlas, 1998). The expectation that eating helps to alleviate affect might predict increases in binge eating (Stice, 2001). Binge eating is therefore likely to be the result of extreme expectations (Smith et al., 2007). Individuals with bulimic symptoms appeared to differ from individuals with anorexic symptoms and controls in their expectations that eating would help them regulate their negative affect. Psychiatric and normal control participants generally did not differ from each other, indicating that expectations scores do not reflect general psychiatric distress (Hohlstein et al., 1998).

The aim of the present study was to test the relationship between expectations regarding the effect of eating on mood, changes in mood, and actual caloric intake in individuals with BED. Our research questions were twofold:

(1) Do expectations regarding food and mood have an effect on caloric intake? We expected that participants with high expectations that food will improve mood to have a larger caloric intake when in a negative mood than participants with low expectations.

(2) Do depressive symptoms influence caloric intake and is there an interaction effect with mood induction? We hypothesized that participants with severe depressive symptoms, especially those with a negative mood induction, would have a higher caloric intake than participants with no-to-mild depressive symptoms.

\section{Method}

\section{Participants}

Participants in this study were 73 non-pregnant females between 18 and 60 years old with a primary diagnosis of binge eating disorder (BED) according to DSM-IV criteria (American Psychiatric Association, 1994) or subthreshold BED (an average of one binge eating episode a week).

To be included in the study, a participant had to report an average of one binge eating episode a week over the previous 24 weeks. Women with a subthreshold BED were also included in the study because they do not seem to differ significantly from patients with full-syndrome BED (an average of two or more binge eating episodes a week) (Striegel-Moore et al., 2000). If participants were on medication, they could participate in the study if they were stable on medication. Participants were recruited from clinics specializing in treating eating disorders $(n=34 ; 47 \%)$, by advertisements in local newspapers, and via Internet websites $(n=37$; $53 \%)$.

The Dutch Medical Ethics Committee for Mental Health Institutions approved the study.

\section{Measures}

\section{Demographic variables}

Participants' marital status, socioeconomic status (homemaker/ retired, fulltime job/student, part-time job, or disabled), educational level (low, medium, high), and age were recorded.

\section{Eating Disorder Examination}

The Eating Disorder Examination (EDE) (Cooper \& Fairburn, 1987; Jansen, 2000) is an investigator-based, semistructured interview for the assessment of eating disorder-specific psychopathologies. The EDE assesses the psychopatholgy of the participant in the previous 4 weeks. It provides a comprehensive profile of individual psychopathology based on scores on four subscales: restraint (e.g., attempts to avoid certain foods), eating concern (e.g., concern about being seen while eating), shape concern (e.g., importance of body shape in self-evaluation), and weight concern (e.g., dissatisfaction with body weight). A global scale of eating pathology (computed as the mean of the participants' scores on the four subscales) is also computed to assess overall eating psychopathology. Items are rated on 7point forced-choice scales (0-6), with higher scores reflecting greater severity or frequency. The EDE also assesses two key behavioral aspects of eating disorders: overeating and the use of extreme methods of weight control. Weight and height were also assessed and Body Mass Index (BMI) was calculated (weight/height ${ }^{2}$ ).

\section{Beck Depression Inventory-II}

The Dutch version of the Beck Depression Inventory-II (Beck, Steer, \& Garbin, 1988; Van der Does, 2002) contains 21 items, each with four self-evaluative statements rated on severity (scored from 0 to 3 ). The BDI-II measures severity of depressive symptoms. The total score is a simple sum of the 21 individual item scores and may range from 0 to 63 . For patients diagnosed as having an affective disorder, the following guidelines are suggested as BDI cut-off scores: no or minimal depression, $<13$; mild depression, 14-19; moderate-to-severe depression, 20-28; and severe depression, 29-63. The internal consistency of the Dutch version of the BDI-II is high for a psychiatric outpatient group and a healthy control group: in tests, Cronbach's alpha was 0.92 and 0.88 respectively. Test-retest reliability correlation in the same groups was $r=0.82$.

\section{Taste task and food intake}

During the taste task, each participant was asked to take a seat behind a table with four pre-weighted bowls with large quantities of food: chocolate $(M=813 \mathrm{~g} / 4352 \mathrm{kcal}$, S.D. $=102 \mathrm{~g} /$ $548 \mathrm{kcal})$, potato chips $(M=149 \mathrm{~g} / 797 \mathrm{kcal}), \quad$ S.D. $=27 \mathrm{~g} /$ $145 \mathrm{kcal})$, candies $(M=616 \mathrm{~g} / 2229 \mathrm{kcal}, \quad$ S.D. $=62 \mathrm{~g} / 226 \mathrm{kcal})$, and cake $(M=464 \mathrm{~g} / 1950 \mathrm{kcal}$, S.D. $45 \mathrm{~g} / 187 \mathrm{kcal})$. In the taste test, participants rated the four kinds of foods on palatability, enticement to eat, taste, and smell (Dingemans, Martijn, Jansen, \& van Furth, 2009). Filling out the questionnaire gave participants a chance to consume the foods. Data were not analyzed except the item that measured how much (from 'not at all' (0) to 'very much' (5)) they liked the four kinds of food. The total amount of food left was measured afterwards and total caloric intake was calculated. 


\section{Manipulations}

Food-mood expectation manipulation

We developed a computerized questionnaire with pre-programmed feedback to induce different expectations about the relationship between food and mood. We presented the questionnaire as a means "to test your knowledge about food," the Fact or Fiction Food Questionnaire (FFFQ). Ten statements about food, each of which had a link between food and emotions, and five filler statements, were displayed on a computer screen. Participants had two reply options, 'true' or 'false.' Immediately after answering each statement, they received feedback on their answer. The participants in the confirmative condition were given the version in which the relationship between food and mood was positively confirmed (confirmative version) and the participants in the disconfirmative condition received the version of the FFFQ in which the positive relationship between food and mood was disconfirmed (disconfirmative version). For example, the first statement was, 'Chocolate contains substances that make you happy'. In the confirmative condition, the participant received the following feedback if she answered 'true': 'Indeed, chocolate contains fenylethylamine which makes you happy' and If she answered 'false', 'On the contrary, chocolate contains fenylethylamine which makes you happy'.

In the disconfirmation condition she received the following feedback if she answered 'true': 'Chocolate does not make you feel happy. Chocolate contains a small concentration of fenylethylamine, which could only make you happy if you ate large quantities of it, such as a truck container'. If she chose 'false', 'Indeed, this is true. Chocolate does not make you feel happy. Chocolate contains a small concentration of fenylethylamine, which could only make you happy if you ate large quantities of it, such as a truck container' (see Appendix 1 for complete questionnaire).

\section{Mood-induction}

Participants were instructed to watch a 3-min fragment of a movie, either from The Champ (negative mood induction) or When Harry met Sally (positive mood induction), to which they were randomly assigned. Studies by Gross and Levenson (1995) showed that these fragments of the two movies elicit sadness and amusement, respectively. All participants received the same instruction: 'In a moment, you will see a fragment of a movie. This fragment may evoke emotions. Watch the fragment with attention and let in the emotions you feel and react to them as you please. Before the fragment starts, the screen will be blank for a minute. Try to clear your mind of all thoughts and emotions. I will leave you alone while you watch the fragment and will return afterwards'.

\section{Manipulation check}

\section{Eating Expectancy Inventory (EEI)}

The EEI (Hohlstein et al., 1998) is a 34-item self-report measure of expectations about the consequences of eating. It consists of five subscales. The present study used two relevant subscales: "Eating helps manage negative affect" (in this study, Cronbach's alpha $=0.87$ ) and "Eating is pleasurable and useful as a reward" (in this study: Cronbach's alpha $=0.70$ ). The subscale "Eating helps manage negative affect" consists of 18 items. Examples of items are "Eating can help me bury my emotions when I don't want to feel them" and "Eating helps me forget or block out negative feelings like depression, loneliness or fear." The other subscale, "Eating is pleasurable and useful as a reward," consists of 6 items. Examples of items are "When I do something good, eating is a way to reward myself" and "Eating is fun and enjoyable." Mean total scores of the two subscales ranged from 1 to 7 . A higher score indicated higher expectations.
Mood scale (adapted from Martijn et al., 2002)

Current mood state was measured by seven adjectives (sad, tense, tired, cheerful, active, irritated, and gloomy) on a $100 \mathrm{~mm}$ Visual Analogue Scale (VAS) on which the end points were labeled "not at all" and "extremely." The mean score of these seven adjectives were calculated (in this study Cronbach's alpha $=0.82$ ). Five items (sad, tense, tired, irritated, and gloomy) were recoded such that a lower score indicated a more negative mood.

\section{Suspicions and awareness}

Participants completed a funneled debriefing form (Bargh \& Chartrand, 2000), which checked for awareness and suspicion.

\section{Procedure}

Respondents $(N=103)$ who reacted to the call for a study on "perception and reactions of persons with binge eating episodes" in local newspapers and at websites and through posters in the waiting room of general practitioners were first screened by telephone or email in regard to the inclusion and exclusion criteria. All patients $(N=50)$, who were on a waiting list for a treatment and fulfilled the criteria of BED, were approached to participate in the study. Potential participants $(n=153)$ were sent an information letter, a screening questionnaire, and the Eating Expectancy Inventory (EEI) (Hohlstein et al., 1998). The EEI was used to measure baseline (T0) expectations regarding eating. Eighty individuals did not participate in the study because of a lack of interest (for example the distance was too far to the centre, monetary reward too low, too much investment in the matter of time) $(n=67)$ or not meeting inclusion criteria $(n=13)$. In total, 73 individuals participated in the study and were invited to the Centre for Eating Disorders "Ursula." All participants signed an informed consent form and received a monetary reward of 15 Euros. The total duration of the experiment was one and a half hours. Participants were instructed not to eat $2 \mathrm{~h}$ prior to the assessment and were tested individually. They were randomly allocated to one of the four conditions from a 2 (Food/mood repair expectation confirmation versus expectation disconfirmation) by 2 (Mood induction, positive versus negative) between-subjects factorial design.

Before the start of the experiment, each participant was interviewed by means of the Eating Disorder Examination (EDE) (Cooper et al., 1987) to confirm the diagnosis of BED (Jansen, 2000) and asked to fill out the Beck Depression Inventory-II (BDI-II) (Van der Does, 2002). After completion of the interview and questionnaire, the participant was seated in front of a monitor. Then, food/mood expectations were manipulated. The participant filled out the Fact or Fiction Food Questionnaire (FFFQ) on the computer. The participant filled out the EEI again to check the manipulation. Before the mood induction (movie fragment) started, the participant filled out the mood questionnaire (T1). After each participant watched the movie fragment, her mood was measured again (T2). Subsequently she took part in the 15-min taste task. The four bowls with food were placed on a separate table previously masked by a folding screen. The participant was instructed to taste all four kinds of food and to fill out the taste perception questionnaire. She was instructed to evaluate the food, and she was told to feel free to eat as much as she liked or thought was necessary to evaluate each food. During the taste task, participants were left alone in order to minimize uncomfortable or negative feelings that might have arisen if someone watched them eat. The time allotted for assessment was the same for all four conditions. After the taste task, the participant filled out the mood scales again (T3), and completed the questionnaire to assess feelings about loss of control, perceived quantity eaten during the taste task, and suspicions about the purpose of the study. At the end of the 
Table 1

Baseline characteristics of all participants ${ }^{\mathrm{a}}$.

\begin{tabular}{|c|c|c|c|}
\hline & $\begin{array}{l}\text { All participants } \\
(N=73)(M, S . D .)\end{array}$ & Range & $\begin{array}{l}\text { Statistical tests for the four conditions } \\
\text { and significance }\end{array}$ \\
\hline Objective binges episodes/28 days & $10.7 \pm 14.8$ & $2-84$ & $F(3,69)=0.75, n s$ \\
\hline Subjective binge episodes/28 days & $10.1 \pm 14.8$ & $0-100$ & $F(3,69)=1.70, n s$ \\
\hline Overeating episodes/28 days & $2.3 \pm 5.1$ & $0-28$ & $F(3,69)=0.72, n s$ \\
\hline EDE Restraint & $1.63 \pm 1.08$ & $0-4.80$ & $F(3,69)=0.72, n s$ \\
\hline EDE Concern about eating & $1.73 \pm 1.22$ & $0-5.40$ & $F(3,69)=0.31, n s$ \\
\hline EDE Concern about weight & $3.28 \pm 1.36$ & $0.40-5.60$ & $F(3,69)=0.58, n s$ \\
\hline EDE Concern about shape & $3.00 \pm 1.34$ & $0.63-6.00$ & $F(3,69)=0.55, n s$ \\
\hline BMI & $34.7 \pm 7.8$ & $21.0-57.44$ & $F(3,69)=0.69, n s$ \\
\hline BDI (depressive symptoms) & $22.6 \pm 11.6$ & $0-47$ & $F(3,67)=0.61, n s$ \\
\hline Mood (VAS) baseline $(0-100 \mathrm{~mm})$ & $43.7 \pm 19.5$ & $10-96$ & $F(3,69)=0.53, n s$ \\
\hline EEI eating alleviates negative affect & $4.79 \pm 1.08$ & $1.33-6.61$ & $F(3,61)=1.66, n s$ \\
\hline EEI pleasurable and useful as reward & $4.97 \pm 1.38$ & $1.00-7.00$ & $F(3,61)=0.78, n s$ \\
\hline
\end{tabular}

${ }^{a}$ Mean scores of the total group are presented since there were no significant differences on baseline characteristics between the four conditions.

experiment, participants filled out the mood scales one last time (T4) and were fully debriefed.

There were thus four participant conditions. Confirmative Positive $(\mathrm{CP})$ and Confirmative Negative $(\mathrm{CN})$ received confirming feedback about the relationship between mood and food but one group saw a mood-uplifting movie fragment, the other a sad one. Disconfirmative Positive (DP) and Disconfirmative Negative (DN) received disconfirming feedback about food and mood followed by either positive or negative movie fragment.

\section{Statistical analyses}

Possible pre-experiment differences between the four condition cohorts in regard to demographics and clinical variables, differences in levels of expectation, negative affect, and mood during mood induction were checked by means of independent sample t-tests, AN(C)OVA, or chi-square tests where appropriate. Subsequently, the three hypotheses, i.e. the three research questions, were tested by means of linear regression analyses. The dependent variable 'total caloric intake' was log-transformed because it was not distributed normally.

\section{Results}

\section{Participant characteristics}

No differences were found between the four conditions with respect to the demographic variables socioeconomic status $\left(\chi^{2}(6)=0.37, n s\right)$ or level of education $\left(\chi^{2}(6)=4.4, n s\right)$. Participants in the negative mood induction condition lived more often alone than those in the positive mood condition (marital status $\left(\chi^{2}(3)=12.6, p<0.01\right)$. Participants in Confirmative Negative (CN) and Disconfirmative Positive (DP) were significantly older $(M=45.6$, S.D. $=10.0$ and $M=41.2$ S.D. $=7.3$, respectively $)$ than participants in the Confirmative Positive (CP) and Disconfirmative Negative (DN) condition $(M=35.2$, S.D. $=10.7$ and $M=32.6$, S.D. $=10.9$ respectively $)(F(3,69)=6.73, p<0.01)$. Forty-seven percent of the participants were currently on a waiting list for treatment and $53 \%$ of the participants had never sought treatment for binge eating.

There were no significant differences between the four conditions in regard to the clinical variables (see Table 1). All participants stated on the Taste Test Questionnaire that they liked at least two kinds of food (score 3 or higher). None of the participants reported any awareness of the true nature of the hypothesized connection between the mood induction, changes in expectations regarding food, and the taste test.

\section{Manipulation checks}

\section{Expectation manipulation}

A 2-between $\times 2$-within ANOVA was conducted with the factors "food/mood repair expectations" (confirmative versus disconfirmative condition) and time (T0 versus T1) as independent variables and scores on the EEI subscale "eating helps manage negative affect" as the dependent variable. We failed to find the predicted interaction effect $(F(1,63)=0.49, n s)$ (confirmative condition: T0: $M=4.93$, S.D. $=1.04 ;$ T1: $M=4.85$, S.D. $=1.15$ and disconfirmative condition: T0: $M=4.65$, S.D. $=1.11$; T1: $M=4.45$, S.D. = 1.24).

Subsequently, a 2-between $\times 2$-within ANOVA was conducted with the "food/mood-repair-expectation" factors (confirmative versus disconfirmative condition) and time (T0 versus $\mathrm{T} 1$ ) as the independent variables and scores on the EEI subscale 'eating is pleasurable and useful as a reward' as the dependent variable. A significant interaction effect was found $(F(1,63)=4.08, p<.05$; $\left.\eta^{2}=0.06\right)$. Participants who were confirmed in their expectation that food and emotions are positively linked (confirmative condition) showed a significant increase in the expectations that eating is pleasurable and useful as a reward after the manipulation (T0: $M=4.85$, S.D. $=1.34 ;$ T1: $M=5.28$, S.D. $=1.17$ ) whereas the participants in the disconfirmative condition did not (T0: $M=5.08$, S.D. $=1.43 ; \mathrm{T} 1: M=5.11$, S.D. $=1.36$ ).

In sum, the manipulation of the expectations (confirm versus disconfirm) did not succeed in changing expectations that 'eating helps to manage negative affect' but succeeded in changing expectations that 'eating is pleasurable and useful as a reward' did: participants in the 'confirmative' condition had significantly higher scores on the subscale "pleasure/reward' of the EEI than participants in the 'disconfirmative' condition.

\section{Mood induction}

A 2-between $\times 2$-within ANOVA was conducted with the factors mood induction (negative versus positive condition) and time (T1 versus T2). As expected, there was a significant interaction effect of time $\times$ mood induction $(F(1,71)=55.6, \quad p<.001$; $\eta^{2}=0.43^{1}$ ), indicating that the mood of the participants in the negative mood induction condition became more negative after watching the upsetting movie fragment $\left(M_{\text {negative }} \mathrm{T} 1=58.3\right.$, S.D. $=20.8$ and $M_{\text {negative }}$ T2 $=49.1$, S.D. $=18.5$ ) and the $\operatorname{mood}$ of the participants in the positive mood induction more positive after watching the cheerful movie fragment $\left(\left(M_{\text {positive }} \mathrm{T} 1=54.4\right.\right.$, S.D. $=18.3$ and $M_{\text {positive }} \mathrm{T} 2=68.8$, S.D. $\left.=17.1\right)$; see also Fig. 2: $\mathrm{T} 1-\mathrm{T} 2)$. Thus, we conclude that the film fragments had the

\footnotetext{
${ }^{1}$ This might be considered a large effect-size (Cohen, 1988).
} 
intended effect of inducing a negative and a positive mood state respectively.

Hypothesis 1. Do expectations regarding food and mood have an effect on caloric intake?

We hypothesized that participants with increased expectations that food will improve mood (confirmative condition) have a larger caloric intake after a negative mood induction compared to participants with decreased expectations (disconfirmative condition).

In order to test this first hypothesis about the effect of changes in 'food/mood-repair-expectations' and mood on caloric intake, we conducted a linear regression analysis with caloric intake as dependent variable and mood induction (negative versus positive), 'food/mood-repair-expectations' (confirmative versus disconfirmative condition) and their interaction as main predictors. No main effects for 'mood induction' $(\beta=-.14, t(72)=0.57, n s)$ and 'food/mood-repair expectation' $(\beta=.18, t(72)=.79$, ns $)$ were found. Also, the expected interaction effect $(\beta=.13, t(72)=0.39$, $n s$ ) between these two variables could not be confirmed. ${ }^{2}$ Thus, no differences were found between the four conditions with regard to calories consumed (Confirm Negative (CN): $M=356 \mathrm{kcal}$, S.D. $=288$; Confirm Positive $(C P): M=376 \mathrm{kcal}$, S.D. $=235$; Disconfirm negative (DN): $M=453 \mathrm{kcal}, \quad$ S.D. $=321$; Disconfirm Positive (DP): $\mathrm{M}=484 \mathrm{kcal}$, S.D. $=334$ ).

Subsequently, we tested whether the degree of expectations (baseline) as measured by the EEI prior to mood induction (T1) had an effect on caloric intake. Do expectations that 'eating will alleviate negative affect' or expectations that 'eating is pleasurable and useful as a reward' moderate caloric intake? In other words, do participants with high scores on the EEI have a higher caloric intake?

Again, we conducted a linear regression analyses with caloric intake as the dependent variable and mood induction (negative versus positive), EEI (subscale "alleviate negative affect") at T1, and the interaction between EEI scores and mood induction as the independent variables. No main effect of expectations at $\mathrm{T} 1$ that eating alleviates negative affect $(\beta=0.004, t(69)=0.05, n s)$ and no interaction effect between these expectations and mood induction was found $(\beta=0.10, t(69)=0.65, n s)$.

Finally, we performed a linear regression analyses with caloric intake as the dependent variable and mood induction (negative versus positive), EEI subscale 'pleasurable and useful as a reward' at T1and the interaction with mood induction as predictors. We found a significant main effect for the EEI subscale eating is pleasurable and useful as a reward' $(\beta=0.27, t(69)=3.10, p<.01)$ and a significant interaction effect with mood induction $(\beta=-0.34, t(69)=2.53, p=.014)\left(f^{2}=0.15^{3}\right)$. Lower expectations that eating is pleasurable and useful as a reward were related to a lower caloric intake after a positive mood induction. No significant correlation with these expectations and caloric intake was found after a negative mood induction.

Hypothesis 2. Do depressive symptoms have an effect on caloric intake and is there an interaction with mood induction? We hypothesized that participants with severe depressive symptoms (as measured by the BDI-II) would have a higher caloric intake, especially after a negative mood induction, than participants with no-to-mild depressive symptoms.

To test this second hypothesis that the level of depressive symptoms (as measured by the BDI-II) would moderate caloric intake after a negative mood induction, but not after positive mood

\footnotetext{
${ }^{2}$ Correcting for age and BMI did not change the results.

3 This might be considered a medium effect-size (Cohen, 1988).
}

induction, we conducted a linear regression analysis with caloric intake as dependent variable and mood induction (negative versus positive), depressive symptoms (BDI-II), and an interaction term (BDI-II $\times$ mood induction) as independent variables. The total group was split by means of the BDI-II into a moderately-toseverely depressed group ( $n=45$; BDI-II score 20 or higher; $M=29.6$, S.D. 7.5), and a non-to-mildly depressed group ( $n=26$; BDI-II score between 0 and 19; $M=10.35$, S.D. $=5.7$ ). The two groups (no-to-mild versus moderate-to-severe depressive symptoms) did not differ in the degree of BMI $(t(71)=-1.3, n s)$ or age $(t(71)=-0.18, n s)$. However, the participants with moderate-tosevere depressive symptoms had more objective binge episodes in the past 28 days $(M=14.7 ;$ S.D. $=17.5)(t(50)=-3.9, p=0.03)$ and had more concerns about weight $(M=3.6$; S.D. $=1.3)(t(71)=-2.5$, $p=0.016)$ and shape $(M=3.3 ;$ S.D. $=1.2)(t(71)=-2.5, p=0.016)$ than the participants with no-to-mild depressive symptoms (frequency objective binge eating episoded $(M=4.2$; S.D. $=4.0$ ); concerns about weight $(M=2.8 ;$ S.D. $=1.3)$ and concerns about shape $(M=2.5$; S.D. $=1.5)$.

No significant main effect of depressive symptoms was found $(\beta=-0.18, t(69)=0.79, n s)$. A significant interaction effect of mood induction and depressive symptoms was found $(\beta=0.82$, $t(69)=2.47, p<0.05)\left(f^{2}=0.11\right)$. After negative mood induction, the participants with no-to mild symptoms $(M=270$, S.D. $=172)$ consumed fewer calories than the participants with moderate-tosevere depressive symptoms $(M=491$, S.D. $=340)(\beta=0.64$, $t(33)=2.79, p>0.01)$. In contrast, caloric intake within the positive mood induction condition was unrelated to the severity of depressive symptoms $(\beta=-0.18, t(36)=0.76, n s)$ (no-mild depressive symptoms $M=455$, S.D. $=295$; moderately severe depressive symptoms $M=414$, S.D. $=292$, see Fig. 1.)

To test whether changes in mood after the mood induction (T1T2) had an effect on caloric intake we added mood change scores (T1-T2) and an interaction term (Mood T1-T2 $\times$ Mood Induction). Mood change scores (T1-T2) were calculated by subtracting the mood score at the beginning of the mood induction (T1) from the mood measurement at the end of the mood induction (T2). We found a significant interaction effect $(\beta=0.031, t(67)=2.2$, $p<0.05)\left(f^{2}=0.19\right)$. Larger negative mood changes during the negative mood induction resulted in a higher caloric intake $(\beta=0.033, t(34)=3.06, p<0.01)$. In the positive mood induction condition, caloric intake appeared to be unrelated to the degree of mood change $(\beta=-0.007, t(37)=1.00, n s)$.

\section{Course of mood over time}

A 2-between $\times 4$-within ANOVA (repeated measures) test was conducted with the factors mood induction (negative versus positive condition) and time (T1, T2, T3 versus $\mathrm{T} 4$ ) to evaluate the course of mood during the experiment. As expected, there was a

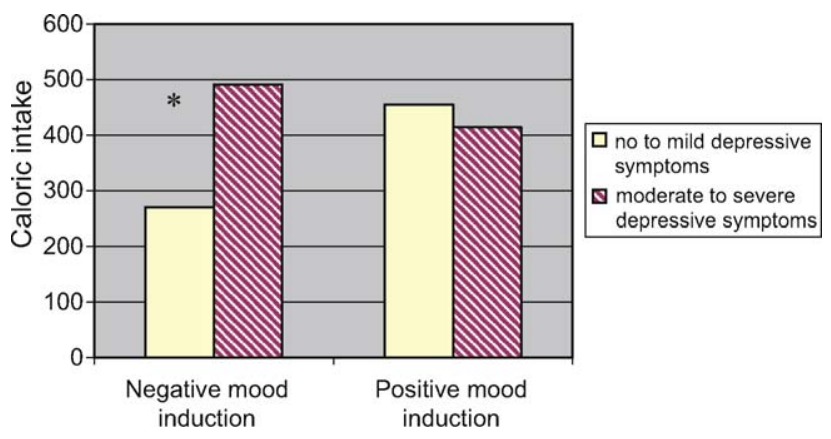

Fig. 1. Mean caloric intake after a negative or a positive mood induction in BED participants with no-to-mild (open columns) or moderate-to-severe (shaded columns) depressive symptoms. 


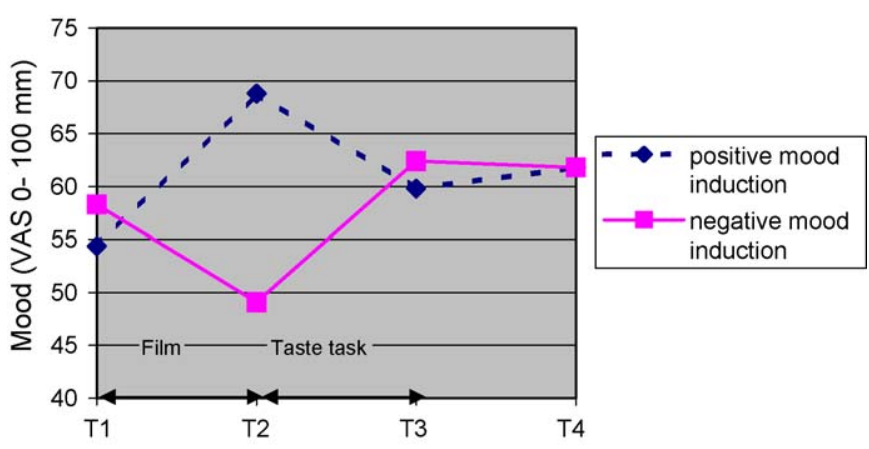

Fig. 2. Changes in mood of patients with binge eating disorder.

significant interaction effect of time $\times$ mood induction $(F(3,67)=$ $21.19, p<.01$ ) (see Fig. 2). As stated above, contrast analyses (T1 versus T2) revealed that the mood of the participants receiving the negative mood induction became sadder after watching the negative movie fragment and the mood of the participants during the positive mood induction more cheerful after watching the positive movie fragment $\left(\eta^{2}=0.43\right)$.

Furthermore, contrast analyses (T2-T3) indicated that the mood of the participants in the negative mood induction condition became significantly more cheerful after the taste task and that the mood of the participants in the positive mood induction more sad after the taste task $(F(1,69)=30.28, p<0.01)\left(\eta^{2}=0.30\right)$. Mood remained unchanged for both conditions between T3 and T4 $(F(1,69)=0.92, n s)$.

Finally, a significant overall main effect of time was found $(F(3,67)=3.73, p<.05)\left(\eta^{2}=0.04\right)$. The participants in both mood conditions had a significantly more positive mood at the end of the experiment (T4) compared to the beginning (T1).

\section{Discussion}

The aim of the present study was to test the relationship between expectations regarding the effect of eating on mood, changes in mood, and actual caloric intake in individuals with BED. Participants were either randomly assigned to a 'confirmative' condition in which expectations that food and mood are related, were confirmed or to a 'disconfirmative' condition in which these expectations were disconfirmed. Subsequently participants were randomly assigned to either a negative or a positive mood induction procedure. Finally, everyone participated in the same taste task. Our main dependent variable was caloric intake during a taste test.

Contrary to our expectations, we did not find a main or interaction effect of food/mood repair-expectations (confirmative versus disconfirmative condition) or of mood induction (negative versus positive) on caloric intake. The participants in all four conditions ate comparable amounts of calories. After the 'fact-or fiction food' mood manipulation, participants in the 'disconfirmative' condition did not have significantly lower expectations that eating would alleviate negative affect than participants in the 'confirmative' condition. Clearly our manipulation was not long or strong enough to alter the expectations of individuals with BED that eating alleviates negative mood. The majority of the participants had had binge eating episodes for many years, which makes it possibly hard to alter potentially long-standing associations between mood and food. However, after completing the manipulated questionnaire, participants in the 'confirmative' condition were significantly more firmed in their expectation that eating is pleasurable and useful as a reward than the participants of the 'disconfirm' condition. Participants in the positive mood induction, who had higher degree of baseline expectations that food is pleasurable and useful as a reward, consumed more calories than participants with a lower degree of expectations. The information they received in the confirmative condition was congruent with their expectations that food is pleasurable and useful as a reward. It appears to be far more difficult to alter expectations when the information received is incongruent.

A positive association was found between depressive symptoms and caloric intake after a negative mood induction: participants with no-to-mild depressive symptoms consumed fewer calories than participants with moderate-to-severe depressive symptoms, which we also found in a previous study (Dingemans et al., 2009). After a positive mood induction no significant differences were found in caloric intake between the no-to-mild depressive group and the moderate-to-severe depressive group (see Fig. 1).

The most remarkable finding was that individuals with no-tomild depressive symptoms ate less after a negative mood induction: they seem to have been able to resist the food better than the other three groups. We had expected to find an overall higher caloric after a negative mood induction than after a positive mood induction since several studies have found a positive link between acute negative affect and binge eating (Greeno, Wing, \& Shiffman, 2000; Grilo et al., 1994; Waters, Hill, \& Waller, 2001). However, Cools and others (Cools, Schotte, \& McNally, 1992) also found no differences in caloric intake in a student sample after a positive and a negative mood induction in a student sample. Why do these non-depressed BED-individuals behave differently? Overall, individuals react differently in positive and negative mood states. Different emotions could have a different effect on food intake even in one individual (Macht, 2008). Emotions and current mood influence the decisions that we make. When in a happy mood, people tend to judge stimuli more positively than when in a negative mood and vice versa (Schwarz \& Clore, 2003). Negative affect signals that the environment poses a problem, whereas positive affect signals that the environment is benign. As a result, negative affect may trigger detail-oriented, thinking processes, which are usually responsive in handling problematic situations. In contrast, positive affective states, by themselves, signal no particular need for action, and happy individuals may hence not be motivated to expend cognitive effort unless other goals call for it. It could be hypothesized that when patients with BED experience a negative mood, they want to escape from these negative emotions. Binge eating may be used as a means to escape from these negative thoughts and worries and may in this way help to alleviate emotional stress (Heatherton et al., 1991). BED patients with no-to-mild depressive symptoms seem to be better able to use healthy coping strategies than BED patents with moderate-tosevere depressive symptoms. Depressed people (with BED) are less able to cope with negative moods and are therefore more likely to engage in ineffective coping strategies, such as binge eating. Depressive symptoms such as increased appetite, hopelessness, or feelings of failure may contribute to increased caloric intake (Presnell, Stice, \& Tristan, 2008). Apparently, the non-depressed individuals with BED behave differently when in a positive mood. The positive mood signals that all is well, so they enjoy the moment and do not worry about restricting high calorie food.

Also of interest is the fact that at the end of the experiment, in both mood induction conditions (positive and negative), mood was significantly higher than at baseline. Mood improved again during the taste task after the negative mood induction. That overeating may serve as a means to repair one's negative mood is in accordance with the results of our previous study (Dingemans et al., 2009). The majority of the general population reports positive emotions or feelings such as enjoyment associated with the taste, happiness, and immediate satisfaction while eating high caloric food (Dunn et al., 2008). Also, the fact that food and positive 
moods are being linked, as illustrated in the Introduction by the example of the recent Mars ${ }^{\odot}$ candy bar advertisement campaign, adds to this hypothesis.

Again we found that participants who were more affected by the negative mood induction consumed more calories. In the positive mood condition no relation was found between degree of positive mood changes and caloric intake. Mood decreased after the taste task in the positive mood induction group. Perhaps the awareness of eating (too much) high caloric food engenders feelings of guilt over not restricting food intake. However, on average, at the end of the experiment, mood was more cheerful then at baseline. It is possible that binge eating often occurs when people are in a negative mood, not because negative mood is a trigger for binge eating, but rather because binge eating decreases negative mood (or "improves mood") (Munsch et al., 2008).

For a correct interpretation of the present results, some limitations of our study should be considered. First, studying (eating) behavior in a controlled laboratory setting remains artificial. For example most individuals do not binge eat outside their homes and individuals have different preferences for bingefood. The caloric intake in our laboratory setting is much smaller than objective binge eating episodes in reality. Also, the mood changes induced by the short movie fragments are probably only minor compared to mood changes due to real life events. Nevertheless experimental studies are necessary to study the causality of psychopathological behaviors and thus to study the underlying mechanisms of psychopathological behaviors like binge eating.

Second, as we already mentioned above, our manipulation of the expectations regarding eating was not long or strong enough to alter the expectancies of individuals with BED that eating alleviates negative mood. In a next study this manipulation should be intensified in order to investigate whether changes in expectations leads to changes in caloric intake.

Third, in the study mood changed as a result of the mood induction (both negative and positive) and returned back to baseline after the taste test. It could be argued that the restoration of mood after the taste test was a natural consequence of time and is not attributable to eating. Future BED studies should include a condition without a taste task, in order to evaluate the natural course of mood after a positive or negative mood induction.

In clinical practice it is important to be aware of the fact that for patients with binge eating disorder, positive mood is also a trigger for eating. In general, patients with BED are aware that negative moods are linked with binge eating. The results of this study might indicate that there are different reasons and/or processes for eating in negative and positive moods. However, untreated people with BED generally gain weight (Cachelin et al., 1999; Fairburn, Cooper, Doll, Norman, \& O'Connor, 2000), so making them more aware of the moods which trigger eating episodes might help prevent weight gain.

\section{References}

Agras, W. S., \& Telch, C. F. (1998). The effects of caloric deprivation and negative affect on binge eating in obese binge-eating disordered women. Behavior Therapy, 29, 491-503.

American Psychiatric Association. (1994). Diagnostic and statistical manual of mental disorders, fourth edition (DSM-IV). Washington, DC: American Psychiatric Association.

Antony, M. M., Johnson, W. G., Carr-Nangle, R. E., \& Abel, J. L. (1994). Psychopathology correlates of binge eating and binge eating disorder. Comprehensive Psychiatry, 35, 386-392.

Bargh, J., \& Chartrand, T. (2000). The mind in the middle: a practical guide to priming and automaticity research. In H. Reis \& C. Judd (Eds.), Handbook of research methods in social and personality psychology (pp. 253-285). Cambridge, UK: Cambridge University Press.

Beck, A. T., Steer, R. A., \& Garbin, M. G. (1988). Psychometric properties of the Beck Depression Inventory-25 years of evaluation. Clinical Psychology Review, 8, 77100.
Cachelin, F. M., Striegel-Moore, R. H., Elder, K. A., Pike, K. M., Wilfley, D. E., \& Fairburn, C. G. (1999). Natural course of a community sample of women with binge eating disorder. International Journal of Eating Disorders, 25, 45-54.

Chua, J. L., Touyz, S., \& Hill, A. J. (2004). Negative mood-induced overeating in obese binge eaters: an experimental study. International Journal of Obesity E' Related Metabolic Disorders, 28, 606-610.

Cohen, J. (1988). Statistical power analysis for the behavioral sciences (second ed.). Lawrence Erlbaum Associates.

Cools, J., Schotte, D. E., \& McNally, R. J. (1992). Emotional arousal and overeating in restrained eaters. Journal of Abnormal Psychology, 101, 348-351.

Cooper, Z., \& Fairburn, C. G. (1987). The Eating Disorder Examination: a semi-structured interview for the assessment of the specific psychopathology of eating disorders. International Journal of Eating Disorders, 6, 1-8.

Deaver, C. M., Meidinger, A., Crosby, R., Miltenberger, R. G., \& Smyth, J. (2003). An evaluation of affect and binge eating. Behavior Modification, 27, 578599.

Desmet, P. M. A., \& Schifferstein, H. N. J. (2008). Sources of positive and negative emotions in food experience. Appetite, 50, 290-301.

Dingemans, A. E., Martijn, C., Jansen, A., \& van Furth, E. F. (2009). The effect of suppressing negative emotions on eating behavior in binge eating disorder. Appetite, 51, 51-57.

Dingemans, A. E., Spinhoven, P., \& Van Furth, E. F. (2007). Predictors and mediators of treatment outcome in patients with binge eating disorder. Behaviour Research And Therapy, 45, 2551-2562.

Dunn, K. I., Mohr, P. B., Wilson, C. J., \& Wittert, G. A. (2008). Beliefs about fast food in Australia: a qualitative analysis. Appetite, 51, 331-334.

Fairburn, C. G., Cooper, Z., Doll, H. A., Norman, P. A., \& O'Connor, M. E. (2000). The natural course of bulimia nervosa and binge eating disorder in young women. Archives of General Psychiatry, 57, 659-665.

Greeno, C. G., \& Wing, R. R. (1994). Stress-induced eating. Psychological Bulletin, 115 444-464.

Greeno, C. G., Wing, R. R., \& Shiffman, S. (2000). Binge antecedents in obese women with and without binge eating disorder. Journal of Consulting and Clinical Psychology, 68, 95-102.

Grilo, C. M., Masheb, R. M., \& Wilson, G. T. (2001). Subtyping binge eating disorder Journal of Consulting \&' Clinical Psychology, 69, 1066-1072.

Grilo, C. M., \& Shiffman, S. (1994). Longitudinal investigation of the abstinence violation effect in binge eaters. Journal of Consulting and Clinical Psychology, 62, 611-619.

Gross, J. J., \& Levenson, R. W. (1995). Emotion elicitation using films. Cognition $\mathcal{E}$ Emotion, 9, 87-108.

Heatherton, T. F., \& Baumeister, R. F. (1991). Binge eating as escape from selfawareness. Psychological Bulletin, 110, 86-108.

Hohlstein, L. A., Smith, G. T., \& Atlas, J. G. (1998). An application of expectancy theory to eating disorders: development and validation of measures of eating and dieting expectancies. Psychological Assessment, 10, 49-58.

Jansen, A. (2000). Eating Disorder Examination (EDE 12.0). Interview ter vaststelling van de specifieke psychopathologie van eetstoornissen. Lisse: Swets \& Zeitlinger.

Macht, M., \& Simons, G. (2000). Emotions and eating in everyday life. Appetite, 35, 65

Macht, M., \& Mueller, J. (2007). Immediate effects of chocolate on experimentally induced mood states. Appetite, 49, 667-674.

Macht, M. (2008). How emotions affect eating: a five-way model. Appetite, 50, 1-11.

Macht, M., \& Dettmer, D. (2006). Everyday mood and emotions after eating a chocolate bar or an apple. Appetite, 46, 332-336.

Martijn, C., Tenbult, P., Merckelbach, H., Dreezens, E., \& de Vries, N. K. (2002). Getting grip on ourselves: challenging expectancies about loss of energy after self-control. Social Cognition, 20, 441-458.

Munsch, S., Meyer, A. H., Margraf, J., Michael, T., \& Biedert, E. (2008). Negative mood induction and unbalanced nutrition style as possible triggers of binges in binge eating disorder (BED). Eating and Weight Disorders, 13, 22-29.

Mussell, M. P., Mitchell, J. E., de Zwaan, M., Crosby, R. D., Seim, H. C., \& Crow, S. J. (1996). Clinical characteristics associated with binge eating in obese females: a descriptive study. International Journal of Obesity E' Related Metabolic Disorders, 20, 324-331.

Peterson, C. B., Thuras, P., Crow, S. J., Mitchell, J. E., \& Miller, K. B. (2005). Subtypes of binge eating disorder based on psychiatric history. International Journal of Eating Disorders .

Presnell, K., Stice, E., \& Tristan, J. (2008). Experimental investigation of the effects of naturalistic dieting on bulimic symptoms: moderating effects of depressive symptoms. Appetite, 50, 91-101.

Schwarz, N., \& Clore, G. L. (2003). Mood as information: 20 years later. Psychological Inquiry, 14, 296-303.

Smith, G. T., Simmons, J. R., Flory, K., Annus, A. M., \& Hill, K. K. (2007). Thinness and eating expectancies predict subsequent binge-eating and purging behavior among adolescent girls. Journal of Abnormal Psychology 116.

Stice, E., Agras, W. S., Telch, C. F., Halmi, K. A., Mitchell, J. E., \& Wilson, G. T. (2001) Subtyping binge eating-disordered women along dieting and negative affect dimensions. International Journal of Eating Disorders, 30, 11-27.

Stice, E. (2001). A prospective test of the dual-pathway model of bulimic pathology: mediating effects of dieting and negative affect. Journal of Abnormal Psychology, $110,124-135$.

Striegel-Moore, R. H., Dohm, F. A., Solomon, R. A., Fairburn, C. G., Pike, K. M., \& Wilfley, D. E. (2000). Subthreshold binge eating disorder. International Journal of Eating Disorders, 27, 270-278.

Telch, C. F., \& Agras, W. S. (1996a). The effects of short-term food deprivation on caloric intake in eating-disordered subjects. Appetite, 26, 211-234.

Telch, C. F., \& Agras, W. S. (1994). Obesity, binge eating and psychopathology: are they related? International Journal of Eating Disorders, 15, 53-61. 
Telch, C. F., \& Agras, W. S. (1996b). Do emotional states influence binge eating in the obese? International Journal of Eating Disorders, 20, 271-279.

Tice, D. M., Bratslavsky, E., \& Baumeister, R. F. (2001). Emotional distress regulation takes precedence over impulse control: if you feel bad, do it! Journal of Personality And Social Psychology, 80, 53-67.

Van der Does, A. J. (2002). Beck Depression Inventory-II (BDI-II-NL). Lisse: Swets \& Zeitlinger.

Waters, A., Hill, A., \& Waller, G. (2001). Bulimics' responses to food cravings: is bingeeating a product of hunger or emotional state? Behaviour Research And Therapy, 39, 877-886.

\section{Appendix A. Food-mood-expectancies manipulation: Fact or Fiction Food Questionnaire (FFFQ)}

1. Chocolate contains substances that make you happy.

- Feedback confirmative condition: chocolate contains fenylethylamine, which makes you happy.

- Feedback disconfirmative condition: Chocolate does not make you feel happy. Chocolate contains a small concentration of fenylethylamine, which only could make you happy if you eat large quantities of it, like a container.

2. You need sugar (like in cookies) to function well.

- Feedback confirmative condition: You need sugar to function well. It is a scientific fact that sugar is a carbohydrate. We need carbohydrates every day.

- Feedback disconfirmative condition: On the contrary sugar is addictive and has a counterproductive effect. Try to eat no sugar for 3 days: You start feeling detoxification phenomena like stress, trembling, irritations, sweating, etc.

3. Potatoes (chips) contain 'bad' carbohydrates.

- Feedback confirmative condition: On the contrary, those carbohydrates are good. Potatoes contain vitamin B, C, potassium, phosphorus and dietary fibres and are free of proteins. Potatoes are easily digestible and they dehydrate.

- Feedback disconfirmative condition: Indeed, these 'fast' carbohydrates like sugar and starch, in potatoes (chips) are absorbed in the blood very quickly. This causes an imbalance between blood sugar and insulin, which makes you shaky.

4. Colouring agents, in for example sweets, pep you up and make you active.

- Feedback confirmative condition: Scientific research indeed showed that the colouring agents pep you up when eaten in the right doses. Colouring agents in sweets make you active.

- Feedback disconfirmative condition: Scientific research showed that the effect of colouring agents is negligible.

5. Junk food makes you happy.

- Feedback confirmative condition: Indeed, junk food contains serotonin (a substance in the brain). Serotonin gives you a pleasant feeling.

- Feedback disconfirmative condition: Junk food is addictive. Junk food contains substances that are addictive.

6. When it is hot, eating salty potato chips helps you feel more energetic.

- Feedback confirmative condition: Indeed, when you sweat you loose a lot of salt. The brains need salt to function well. If the level of salt decreases you feel tired and dizzy. Eating salt helps to refill these sources and you feel more energetic afterwards.

- Feedback disconfirmative condition: Human beings only need a little salt. The amounts of salt in food are more then enough even when it is hot and you are transpiring a lot. Salt shortage is very rare in healthy people.
7. Sport drinks do not give you energy.

- Feedback confirmative condition: Sport drinks contain several stimulating substances like caffeine, vitamins, minerals and sugar, which gives you energy immediately.

- Feedback disconfirmative condition: Indeed, an average sportsman with a healthy diet ingests enough minerals. Sport drinks contain a lot of calories, which do not give you more energy.

8. Drinking coffee is stimulating.

- Feedback confirmative condition: Coffee contains the stimulating agent caffeine. Drinking coffee peps you up.

- Feedback disconfirmative condition: Coffee only peps you for a very short period. After drinking too much coffee you feel exhausted, mentally as well as physically.

9. Eating candies and chocolate during the menses worsens the complaints.

- Feedback confirmative condition: On the contrary, eating candies and chocolate helps you to feel better during the menses. It contains substances that work like a antidepressant. Your mood improves.

- Feedback disconfirmative condition: After eating chocolate and candies the level of estrogen (female hormone) raises. This might enhance complaints during the menses and results in more sensitive breasts.

10. Good fats don not exit.

- Feedback confirmative condition: Unsaturated fats are good fats. They help keeping your heart and blood vessels healthy. Oily fish contains omega-3 fatty acids, which enhance your mood and concentration.

- Feedback disconfirmative condition: You only need very small amounts of fat a day. Most fats we eat are very unhealthy like in snacks and cookies.

Filler questions:

11. Fresh vegetables contain more vitamins than canned or frozen vegetables.

Feedback both conditions: Before vegetables are canned or frozen, they are blanched. Therefore preparation time is shortened in comparison to fresh vegetables. After preparation for consumption there is practically no difference in vitamins.

12. It is sensible to drink a lot of orange juice.

Feedback both conditions: One glass of orange juice can replace one piece of fresh fruit. However, the second piece of fruit needs to be fresh.

13. Snacks between meals are important.

Feedback both conditions: Without snacks between meals the body does not receive enough energy for a long time. When the time between meals is too long, this can cause a hypoglycaemia.

14. Without eating meat you can live a healthy life.

Feedback both conditions: A vegetarian diet which contains vegetables, fruits, beans, bread, nuts, cereals and milk product, yields enough nutrients.

15. Food products that contain extra vitamins and minerals are healthier than 'normal' food products.

Feedback both conditions: A normal healthy diet contains enough vitamins and minerals. Normally, adding vitamins and minerals is unnecessary. 